\title{
Potências da Presença no \\ Terreno Movediço de Co-incidências
}

\section{*Milene Lopes Duenha **Francisco Gaspar Neto}

\section{Resumo}

Emergências num percurso delineado pelas questões Como viver junto? e Como não ter uma ideia? colocam em xeque relações estabelecidas na imposição da presença do artista. As ferramentas/ conceitos do Modo Operativo AND, de João Fiadeiro e Fernanda Eugénio, propõem experimentar diferentes relações no fazer artístico e em outras dimensões da vida. Este artigo apresenta as reverberações do contato com a prática do AND Lab, e nosso encontro, como pesquisadores, em uma residência realizada na cidade de Florianópolis SC, na intenção de explorar possibilidades dessa experiência dentro da abordagem da presença do artista no encontro entre corpos em comunidade.

Palavras-chave: criação artística - modo operativo AND - presença - comunidade

\begin{abstract}
Emergences which come up in a field established by the questions How can we live together? and How can we avoid having ideas? destabilize the relationships in the imposition of the presence of the artist. Fernanda Eugenio and João Fiadeiro's Mode Operating AND tools and concepts propose to try different relationships in art making and other aspects of life. This article present reverberations of the contact with the practice of MO AND, and our meeting while researchers, at a residence held in Florianópolis - SC, intent on exploring this approach possibilities within the experience of the presence of the artist in the encounter between bodies in community.
\end{abstract}

keywords: artistic creation - mode operating AND - presence - community

* Bailarina, atriz e performer, doutoranda em Teatro pela Universidade do Estado de Santa Catarina (UDESC). Mestre em Teatro pela UDESC. Email: miduenha@yahoo.com.br

** Professor Assistente da Universidade Estadual do Paraná/Faculdade de Artes do Paraná. Doutorando em Teatro pela Universidade do Estado de Santa Catarina UDESC/Universidade de Lisboa, bolsista do programa de doutorado sanduiche no exterior 
O contato com a proposta de trabalho de João Fiadeiro e Fernanda Eugénio ${ }^{1}$ nos provocou alguns deslocamentos, e os encontros na Residência Modo Operativo $A N D^{2}$, impulsionaram a escrita deste artigo, no qual expomos as reverberações da experiência do viver juntos, e conexões de leituras que se mostram como ferramentas de articulação de um fazer artístico e de um discurso menos vinculado à produção e interpretação de significados, e mais próximo da tangibilidade das presenças. Tratamos do encontro entre presenças, e nos interessamos por encontros que incitam questionamentos acerca do próprio fazer, e do estar no mundo. Este nosso encontro no MO AND nos permitiu uma abordagem da presença e da atenção do artista no ato da composição, enquanto co-partícipe de uma comunidade em construção.

O MO AND baseia-se em dois princípios fundamentais regidos pela modificação da noção de relação: como viver juntos e como não ter uma ideia (EUGÊNIO; FIADEIRO, 2013). O primeiro trata do estabelecimento de uma comunidade que se esquiva daquela de um grupo de indivíduos atuando conjuntamente em um espaço-tempo de atividades pré-determinadas. A comunidade proposta no MO AND tem um caráter radical, já que reverte as noções estabelecidas de sujeitos como agentes protagonistas da experiência, e os coloca em pé de igualdade com objetos e acontecimentos. A noção de jogo é central nesta articulação, porque ele é pensado como nascido de um acidente inicial que, aos poucos, vai fazendo consistir suas regras, seus meios e seus agentes (EUGÊNIO; FIADEIRO, 2013; 2012). Pensado como plano de consistência, o jogo põe em crise tanto a concepção bíblica da criação ex-nihilo, quanto a concepção romântica da criação como resultado do arrebatamento de um sujeito criador (EUGÊNIO; FIADEIRO, 2013). A essência de tal jogo instala-se, desde o início no meio, assim como a meio caminho andado ou em meio às coisas. Abdica-se, deste modo, à consecução lógica dos fatos que se dão entre um fundamento já determinado, e um fim esperado. E meio ambiente que não observa as fronteiras entre sujeitos e objetos, os caminhos e os descaminhos, as figuras e os fundos, mas que emerge como relevo.

A junção das vontades de descobrir modos de fazer que não obedecessem a uma lógica do impulso da criatividade, da hierarquia de valor inerente à atribuição da genialidade, da capacidade individual de se gerir uma grande ideia, calhou no princípio da Secalharidade (EUGÊNIO; FIADEIRO, 2013), prática de improvisação e criação coletiva de paisagens de convivência, resultante do método de Composição em Tempo Real, desenvolvido por Fiadeiro, que se juntou à etnografia como ferramenta para performances que Eugénio explorava. Tal encontro resultou em uma metodologia que se estabelece como jogo no qual todos os envolvidos, com suas ações em favor do coletivo, são responsáveis pela sustentação do encontro, sob a intenção de adiar o seu fim com ações justas. Este termo, aqui, ganha contornos específicos, já que não se trata de obedecer a uma justiça nas ações, mas uma justeza.

A ideia de justiça pressupõe uma lei anterior e exterior ao encontro, algo como um modelo a ser seguido, que, no final das contas, são ideias pré-concebidas e transcendentes. Em muitos momentos, durante a residência, os mal entendidos a respeito dos modos de participação eram causados por um apelo à justiça. A justeza, por outro lado, como pensam Depraz, Varela e Vermesch (2002) fala do modo como as ações se ajustam sem que se perca o seu rigor. João Fiadeiro, em algumas ocasiões, forneceu um exemplo valioso para o que seja a justeza. Quando o jogo muda de centro, mas ainda guarda o plano de composição, tendemos a expressar nossa surpresa com um "Ah", quase um suspiro que nos mostra que fomos afetados por uma pequena mudança no jogo que é como uma diferença que mantém o plano vivo. Porém, quando o jogo muda de plano e todos os elementos da composição participam de forma justa, a comunidade opera e o acontecimento emerge, respondemos com um grito de surpresa, um "Ahá”, como a confirmação da descoberta de uma existência em surgimento.

João Fiadeiro e Fernanda Eugénio (2012), ao definirem o conceito de Secalharidade, impulsionam a abordagem da renúncia ao protagonismo do artista em favor do ato com-positivo propondo um refinamento da escuta e a abertura ao devir. Os autores explicam que a secalharidade é um modo de relação que subtrai a ideia de controle, de manipulação, por uma "ética do manuseamento suficiente" atribuindo ao ato do encontro a

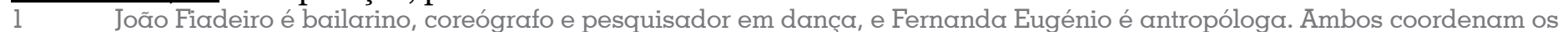

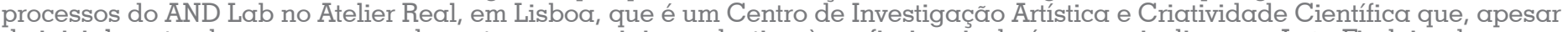

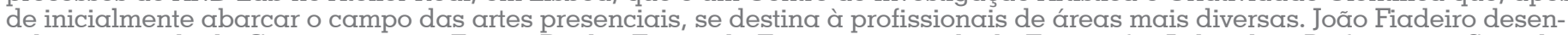

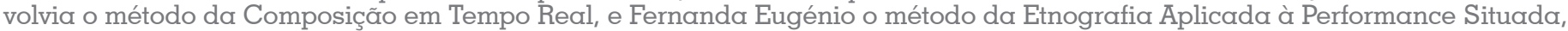

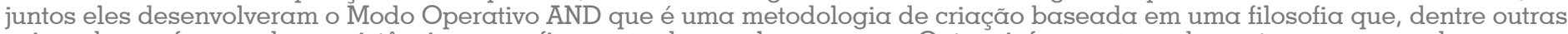

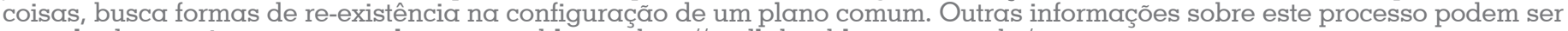
consultadas no site: <www.re-al.org > e no blog: < http://andlabpt.blogspot.com.br/>

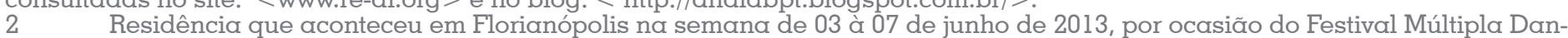

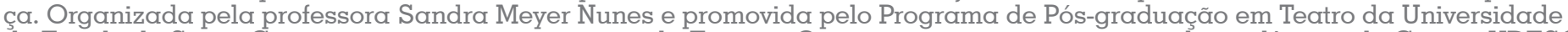

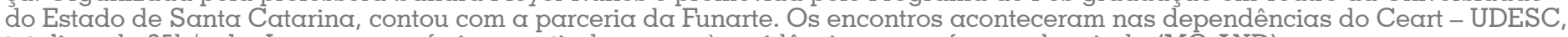
totalizando 25h/aula. Iremos nos referir, a partir de agora, à residência na sua forma abreviada (MO AND). 
potencialidade da medida "justa" na criação de um plano comum, o que possibilita uma "assistência não expectante, desarmada do eu e atenta ao outro" (FIADEIRO; EUGÉNIO, 2012, p. 62).

Neste trânsito da configuração e manutenção de um plano comum, a responsabilidade de geração de potência de afeto é transferida para o acontecimento no encontro entre objetos, corpos e espaço. O estímulo ao participante desse jogo é a possibilidade de intervir pontualmente no que ali, no espaço do aqui-agora, emerge das relações. A pergunta que se faz, antes de cada intervenção, é se ela é justa e está a altura do acontecimento, sendo que a resposta pode ser mesmo abdicar de intervir. Antes de mais nada é necessário não atrapalhar ${ }^{3}$. A ideia genial é abandonada nesse jogo, no qual o objeto, corpo ou evento se revelam como elementos a serem manuseados em sua materialidade, ao invés de serem manipulados a partir de pressupostos subjetivos, lógicos e culturais, identitários e habituais. Deste modo, o exercício da escuta e o do re-parar - que é a perspectiva de não agir espontânea ou instantaneamente, para observar o que se ali se apresenta -, norteiam as ações que só deverão ocorrer se o acontecimento pedir, se calhar.

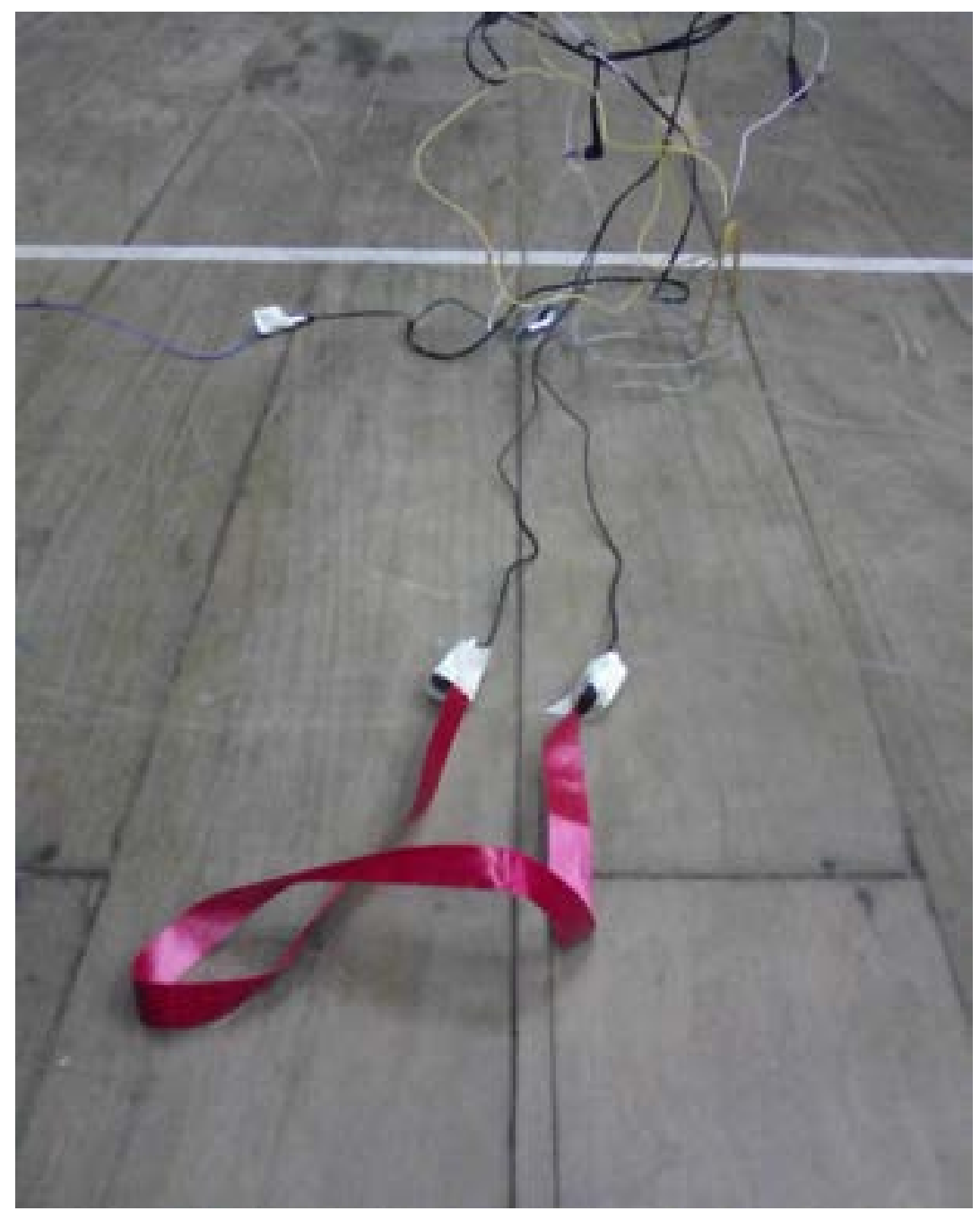

Fig.l - Registro de um dos exercícios realizados no dia 06/06/2013 na residência Modo Operativo AND no CEART-UDESC em Florianópolis - SC. Foto: Acervo pessoal.

E quantos nãos ouvimos de João Fiadeiro e de Fernanda Eugénio no intuito de conter o impulso no decorrer daquela semana de convivência/residência. A vontade de contribuir com uma solução criativa, a cada tomada de posição de um participante, era sempre um empecilho à permissão de emergências pela potência das coisas. O eu e o meu reivindicavam constantemente seus espaços. Aquele metro quadrado, demarcado por fita crepe colada no chão, convidava a infinitas possibilidades de ação, porém, evidenciava também a possibilidade de erro e de acerto diante do desejo de se chegar à medida justa. E nos ensinava também a renunciar à intervenção, porque o justo parecia inalcançável, ou porque exatamente aí residia sua justeza.

3 Há aqui uma referência ao primeiro dos princípios de Esquizoanólise propostos por Guattari (1981, p. 139), "Nã̃o atrapa- 
A configuração de um ambiente em que não se age por uma vontade individual, mas em favor da geração e gestão da comunidade é um instigante desafio, na tentativa de estabelecer uma linguagem plural, mais acessível, e menos carregada de significados. No processo proposto por Eugénio e Fiadeiro a ação deveria ser clara o suficiente para que o outro pudesse operar nesse meio comum. Impor um desejo, esperar que o outro decifrasse nossas intenções subjetivas, aparecia sempre como entrave no percurso. Nesse processo, aparece então a necessidade de desapego para que exista a possibilidade de partilha.

O espaço de partilha é, para Eugénio e Fiadeiro (2012), o lugar de des-autorização, aquilo que Rancière (2005) chama de lugar-comum, no qual as noções de autoria e território podem, e devem, ser questionadas. As figuras de autor/artista desaparecem, o eu só tem vazão na necessidade de continuidade da relação comunitária. Essa é a Ética do suficiente, que torna as ações no convívio, mais justas, favorecendo o que é coletivo em detrimento da individualidade (Eugénio; Fiadeiro, 2012). O que se pretende observar é a emergência do acontecimento na gestão do plano comum da atuação que, por sua vez, surge na relação.

Para Eugénio e Fiadeiro, todos são investigadores, "não há espectadores; não há artistas, somos todos (quer assumamos a responsabilidade ou não) artesãos do nosso próprio convívio" (2012, p. 64). Nesta relação, a resiliência é palavra-convite que emerge como "força flexível da fragilidade adaptativa", exigindo re-aprender a olhar para "lidar com o que se tem e operar na reinvenção, não na negação" (2012, p. 64). A tarefa em favor da "des-cisão" é "re-existir a cada encontro, ser a consequência, e não a causa, da relação" (2012, p. 64). O termo relação surge neste contexto de modo diferente do habitualmente pensado. Não ser a causa da relação significa ser causado por ela, o que coloca em questão os pólos fixos de sujeito e objeto, fato que é central no MO AND e nesta argumentação.

Segundo Simondon (2007), assim como não há indivíduo pronto também não há meio à priori. O que há são duas séries em devir constante, sempre em vias de individuação. O indivíduo para Simondon é múltiplo antes de ser único (COMBES, M., 1999). A individuação coexiste com o indivíduo. Por esse ponto de vista os pólos não são fundamentais, o fundamento é o devir e a relação, aquilo que se passa entre o indivíduo e o meio a ele associado, processo temporal de uma individuação que está sempre em vias de se individuar. O que está na base desse processo é um novo modo de se pensar a relação. Como diz Didier Debaise (2004), Simondon reverte o posicionamento aristotélico pelo qual a relação é a categoria que guarda realidade menos específica. Debaise diz que em Aristóteles a relação carece de realidade superior e, ao mesmo tempo, não passa de elemento constitutivo da substância. Por essa definição a relação é resultado do encontro de termos que a ela preexistem. Toda essa armação teórica faz dos indivíduos prontos os precursores da relação, e esse modo de pensar se estabeleceu como regra quase inviolável para o pensamento ocidental. Simondon (2007) reverte este primado da individuação sobre a relação ao estabelecer um vínculo entre ambas e que faz da relação o centro da individuação, afirmando assim a relação como imanente ao processo de individuação. Na Experiência do MO AND a relação preexistente aos termos possibilita a "com-posição" - tomada de posição com o outro, "pôr-se com" (EUGÉNIO; FIADEIRO, 2012, p. 65) - na "co-dependência” ente as diferenças.

Neste contexto, a noção de embodiment (mente incorporada) é pertinente. Autores como Suzanne M. Jaeger (2006) abordam esta questão a partir da fenomenologia do filósofo francês Maurice Merleau-Ponty para entender a constante reorganização do esquema corporal que se altera a cada nova situação e ambiente ${ }^{4}$. Para Varela, Thompson e Rosch (1991), embodiment é um tipo de reflexão em que o corpo e mente emergem juntos, a partir de um exercício de esvaziamento da mente. O embodiment é constituinte do MO AND, na medida em que o compositor recusa a avaliação objetiva do mundo, pela determinação do olhar, garantida por uma interpretação subjetiva, ao mesmo tempo em que incorpora os afetos circundantes (EUGÉNIO; FIADEIRO, 2012). A reflexão não se dá sobre a experiência, mas ela mesma é um tipo de experiência, que é a de reconhecer os próprios padrões de pensamento, tentando manter a mente aberta e fechada ao mesmo tempo (Mindfful), cortando a cadeia de padrões de pensamento habituais e preconceitos, e abrindo possibilidades para além daquelas contidas nas representações do vivido, num tipo de relação que escapa dos polos objetivos e subjetivos que João Fiadeiro e Fernanda Eugênio chamam de partycipaçãōo (EUGÉNIO; FIADEIRO, 2012).

\footnotetext{
4 O esquema corporal para Meleau-Ponty (1994) seria a maneira de expressão do corpo no mundo, não se tratando de uma mera reunião de órgãos. A espacialidade do corpo diz respeito a uma dinâmica de funcionamento enquanto espacialidade de situação, que se refere ao que ocorre no momento em relação com ambiente em uma perspectiva dinâmica.

Convocar alguém para uma "partycipação" envolve ampliar a membrana do pequeno grupo e abrirmo-nos a uma conversa sobre os modos de estarmos juntos, na partilha das responsabilidades pelo gerir do nosso próprio entorno. Mas como usar o que temos para desenhar um território de "party-cipação" franco e recíproco, quando o que temos são mecanismos de poder que escoam quase irresistivelmente para a representação, a demonstração ou a exposição? E estes, a primeira coisa que fazem é imobilizar o outro, em algum grau, na condição de objeto, retirar-lhe a agência e a responsabilidade, cancelar o convite a ele recém-endereçado, organizar o "evento" e suspender a hipótese do acontecimento como acidente emergente e auto-organizativo.
} 
Segundo Depraz, Varela e Vermesch (2002) a atenção é direcionada ao mundo como uma ação direta e inquisitória. Acessar a experiência por debaixo dessa camada depende de outro tipo de ação, mas sem esforço. O sujeito ainda quer algo muito específico, mas ao invés de agir, ele espera e mantém a mente vazia. Um gesto de conversão da atenção da procura para a espera e mais, um esforço para deixar passar ao invés de cumprir uma determinada tarefa. Esse esforço também diz respeito a um "deixar-vir" aquilo que antes era somente intuído (Depraz, Varela e Vermesch, 2002). E não se trata de um gesto puramente mental, mas de uma ação imanente ao corpo e à mente. A tarefa, é ficar antenado ${ }^{6}$ na experiência, antes de cumprir uma ação, o que Lisa Nelson (2003) chama de sair do registro do looking for para entrar no registro do looking at.

Esse effortless effort (VARELA, THOMPSON E ROSCH, 1991) depende de extremo rigor, e, em alguns casos, pode levar anos de aprendizado e dedicação, embora essa temporalidade não seja essencial no processo. O effortless effort está longe da passividade, ao contrário, é uma proposição ativa de não responder à captura do mundo. É ativo também na medida em que se está antenado com o presente e com o que se passa. A atenção tem de estar sintonizada naquilo que acontece, e com uma justa medida, igual às cordas de um instrumento, nem muito frouxas nem muito apertadas.

É essencial que o compositor esteja antenado nas duas dimensões díspares do acontecimento, e que ao mesmo tempo constituem a ligação entre o dentro e o fora da experiência sem que, entretanto, caia na armadilha de uma conjugação unitária, um diálogo entre iguais, mas mantenha a relação entre grandezas diferentes, originadora do processo de individuação. Nem antes nem depois, mas o agora do acontecimento como condição de partycipação. Assim, ele se instala sobre uma tensão que permite uma abertura para o mundo a partir de uma lógica da diferença. Para o encontro é necessário "revogarmos os escudos protetores seja do sujeito seja do objeto" e, para que isso ocorra é necessário que haja um effortless effort ou o que Eugênio e Fiadeiro (2012), chamam de um retroceder da ação e do eu, um esforço para abdicar das demandas do mundo que convocam ao imediatismo.

A esse respeito, Hans Ulrich Gumbrecht (2010), atribui à cultura da interpretação de significados a consequência do distanciamento da tangibilidade da presença, enquanto Jorge Larrosa Bondía (2002) diz que o ato de nomear as coisas também se liga à atribuição de significado, e à distância da configuração da experiência. Finalmente, Erika Fischer-Lichte (2011) propõe uma abordagem do corpo enquanto fenomênico, permitindo o questionamento das atribuições da semiótica.

Tais posicionamentos mostram uma ação de resistência ao ato de identificar o que as coisas significam, ao invés de tentar a aproximação com o que as coisas apresentam no devir de sua existência, assim como o faz Eugénio e Fiadeiro (2012). O sentido, para não ser conformado em instâncias de significado como nos mostra Deleuze (2007), é compreendido como direção, como vetor. Quais sentidos seriam possíveis para a presença, quando abordada no aspecto da relação, enquanto entre-ter? Quando as presenças potencializam a emergência do acontecimento e de novos sentidos como possibilidade de seguir?

A prática do MO AND resiste na seguinte questão: Como criar condições para que a matéria apareça no acaso? Como preservar a potência e o devir da matéria? O espaço do já saber, da interpretação, da representação, do sentido - que se traduz por importância/valor, não contemplam as emergências, reforçam o "pressuposto do saber para depois agir". "É preciso abdicar das respostas, largar a obstinação por se definir o que as coisas são, o que significam, o que querem dizer, o que representam" (EUGÉNIO; FIADEIRO, 2012, p. 3).

Algumas possibilidades de re-existência surgem então na pausa, na inibição, na vontade de adiar o fim, na possibilidade de identificar a potência de afeto no acidente. Para isso um refinamento da percepção é constantemente solicitado, ver o que a coisa tem, e não o que é, aproveitar o inesperado - achar meios para que ele emerja -, aceitar, retribuir, re-parar são estímulos constantes nessa prática. Tais momentos no percurso dizem respeito à contra-efetuação ininterrupta que sustenta a emergência do encontro. A contra-efetuação é o que Eugénio e Fiadeiro (2013) denominam de handling, termo que na língua inglesa remete tanto a manuseamento quanto a cuidado e assistência.

\footnotetext{
(EUGÉNIO; FIADEIRO, 2012, p. 68). 6 Lisa Nelson desenvolveu um método de Composição baseado no ato de estar antenado, chamado exatamente de Tuning perceptual behaviour can be slowed down, in a sense, and investigated in detail. "Without a camera, how long does it take to see something? How long does it take to look at something? It really is about measuring and the senses are looked at as measuring tools," Nelson explains. "Other things came into the tuning score as well, it was about looking at movement from both sides of the lens, so to speak. What does it mean to look at a movement? What am I doing when I'm looking at a movement? How does a movement organise or have meaning for me or for the person sitting next to me? What gives meaning to my looking at movement? What is arrested motion or stillness, and what happens when you look at it?" (PEETERS, J. Dialogues on Blindness; Lisa Nelson In: Dance Jornal Theatre, United Kingdom, 2005, p. 1)
} 


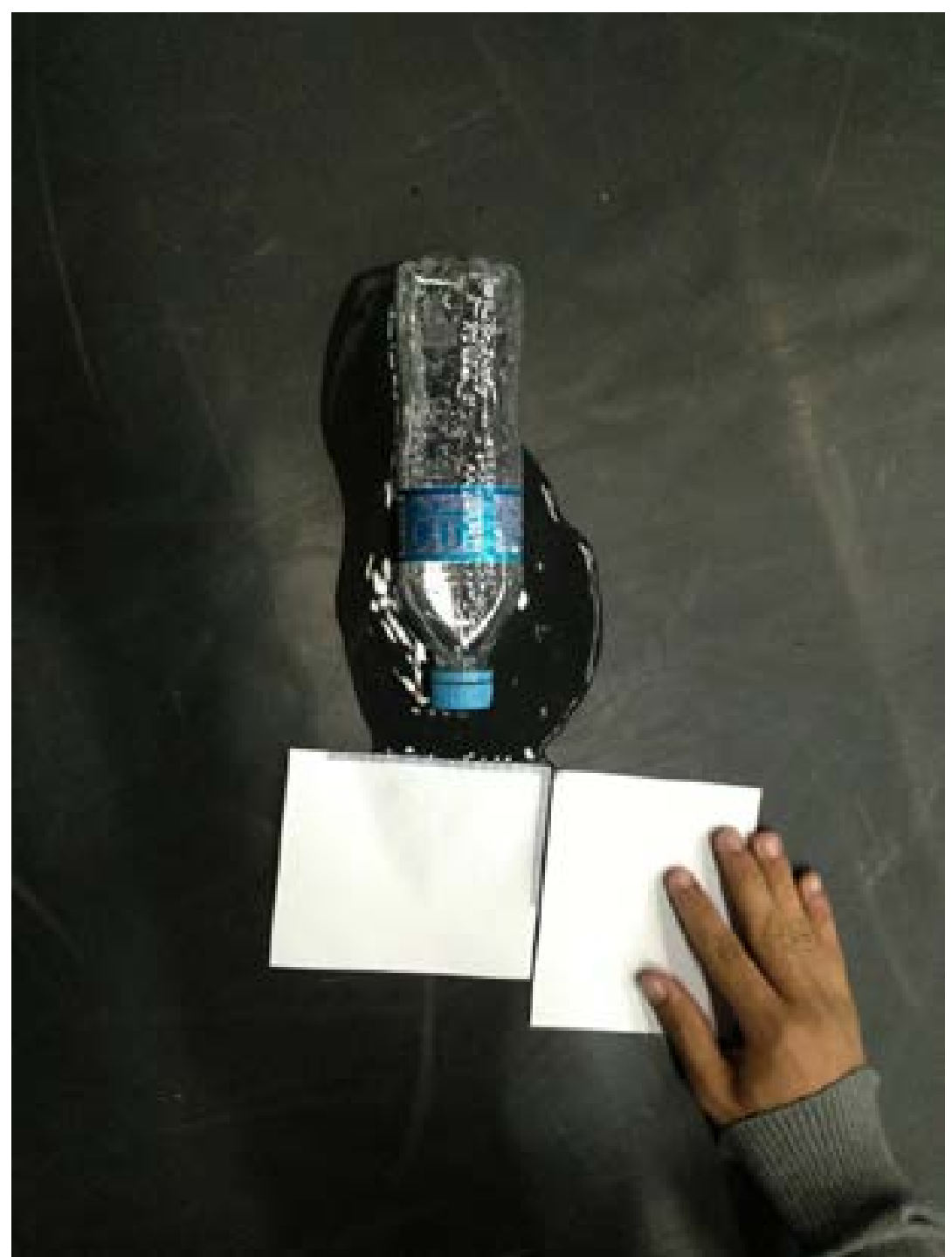

Fig. 2 - Registro de um dos exercícios realizados no dia 04/06/2013 na residência Modo Operativo AND no CEART-UDESC em Florianópolis - SC. Foto: Acervo pessoal.

Na proposta de Eugénio e Fiadeiro, não se pretende uma modulação das ações de modo a se obter um resultado homogêneo, ao mesmo tempo em que o indivíduo não age por ele só, mas em favor do que se estabelece no jogo, entre uma tomada de posição e outra que, por sua vez, considera o aqui-agora, o devir dos corpos, e busca a medida justa. Se a ação potencializa outra ação, se tem affordance ${ }^{7}$, ela aparece então como potência de acontecimento. A incursão no espaço do não-saber, a aceitação do acidente, do não planejado, é um navegar no heterogêneo que dá ocasião para "refundar modos de operar" (EUGÉNIO; FIADEIRO, 2012, p. 1). A certeza, a mania de decifrar e classificar, estão tão arraigadas nos nossos modos de ser que, sequer chegam a abalar nosso habitual jeito de ser.

Uma possibilidade vivenciada no Modo Operativo AND é a insistência na escuta, na atenção ao que está, ou seja, no esforço em respeitar as qualidades do objeto, corpo ou ação em pauta e, no ato de re-parar acionam-se mecanismos de re-existência. Nesta atenção à materialidade emergente da relação se dissolve a hierarquia de valor entre corpo e objeto para a escuta das possibilidades funcionais destes corpos. "O encontro só é mesmo encontro quando a sua aparição acidental é percebida como oferta, aceite e retribuída” (EUGÉNIO;

\footnotetext{
7 Flávio Oliveira e Sérgio Rodrigues (no artigo Affordances: a relação entre agente e ambiente. Ciências e Cognição. Revista interdisciplinar de estudos da cognição. Vol. 09, 2006, p. 129) explicam o termo Âffordance cunhado pelo psicólogo americano James Jerome Gibson como "possibilidades de ação que um ambiente oferece a um agente particular". Os autores colocam que a affordance se relaciona às possibilidades de ação na interação entre o homem (agente) e o ambiente. De acordo com Gibson (apud OLIVEIRA; RODRIGUES, 2006, p. 121-122) "superfícies possibilitam locomoção, alguns objetos possibilitam manuseio e outros animais possibilitam interações sociais" essas seriam as Âffordances "uma combinação específica das propriedades de suas substâncias e suas superfícies tomadas como referências a um animal".
} 
FIADEIRO, 2012, p. 1).

Segundo Eugénio e Fiadeiro substituímos espera por desespero, emergência por urgência, confiança por certeza. Se "viver juntos é, tão somente, adiar o fim" (EUGÉNIO; FIADEIRO, 2012, p. 4), como o faremos tão cheios de razão, de saberes, de pré-conceitos, de pressa? O desespero é o sintoma de uma ficção, a de que detemos o controle sobre os acontecimentos. Inabaláveis no nosso modo de operar habitual, e insensíveis à face de individualização, de devir, da qual também participamos, respondemos impulsivamente quando somos tomados por um acidente que nos rouba essa ficção. Abrimos mão da espera como ação rigorosa e reagimos ao sabor dos afetos, sem ultrapassar os afetos. Resta, no desespero, insistir no sintoma, recrudescer na ficção de controle, regularidade, previsibilidade e identidade. Como dizem Eugênio e Fiadeiro: "a cada coisa o seu nome, o seu enquadramento, a sua regularidade; nenhum susto ou ameaça, tudo explicado e dentro da ordem da previsibilidade. E isso, tudo isto, já não se sustenta mais (EUGÉNIO; FIADEIRO, 2012, p. 3). Em resposta ao sintoma Eugénio e Fiadeiro convidam a re-parar, a

suspender o regime da urgência' criando as condições para uma abertura desarmada e responsável à emergência' Substituir a expectativa pela espera' a certeza pela confiança' a queixa pelo empenho' a acusação pela participação' a rigidez pelo rigor' o escape pela comparência' a competição pela cooperação' a eficiência pela suficiência' o necessário pelo preciso' o condicionamento pela condição'o poder pela força' o abuso pelo uso' a manipulação pelo manuseamento' o descartar pelo reparar 'EUGÉNIO; FIADEIRO, 2012, p. 3).

- Haveremos de ser claros nas propostas! Eugénio e Fiadeiro insistem: - O outro não pode ficar com a tarefa de adivinhar, de supor o que você imaginou, a sua ideia. - Não manipularás! Brinca João Fiadeiro, em outra ocasião. Os objetos, as coisas, os outros, não estão no mundo para serem manipulados ao prazer. A aproximação cuidadosa com as coisas (objetos, pessoas, acontecimentos) de modo a se dissolver hierarquias de atribuição de valor, parece um caminho pertinente à sobrevivência da experiência artística relacional. Aos agentes dessa experiência, a escuta atenta se mostra um elemento a ser explorado na relação entre sujeito e ambiente. Como ser o efeito e não a causa da relação num terreno propositivo como o das artes presenciais? Quer tarefa mais difícil ao artista do que controlar o impulso criativo? Retroceder enquanto presença determinante do acontecimento.

Este seria o convite à ausência, em favor de uma presença justa, que se manifesta no "sabor" do acontecimento gerado no entre, no corpo, na ação ou no objeto, na efetuação dos muitos que compartilham a experiência. Trata-se de um modo avesso de operar, que vai contra os muitos anos de defesa da vazão à subjetividade individual, do acesso à grande ideia, da arte enfim.

\section{Referências}

BONDÍA, J. L. Notas sobre a experiência e o saber de Experiência. Universidade de Barcelona, Revista Brasileira de Educação, Trad. João Wanderley Geraldi, Unicamp, Espanha. 2002. Disponível em: <http://www.anped. org.br/rbe/rbedigital/RBDE19/RBDE19_04_JORGE_LARROSA_BONDIA.pdf >. Acesso em: 15 mar. 2013. COMBES, Muriel. Simondon. Individu et collectivité. Paris: PUF, 1999.

DEBAISE, D. Les conditions d'une pensée de la relation Selon Simondon in: Simondon, P. Chabot (ed.), Paris: Vrin, 2004. pp. 53-68.

DELEUZE, Gilles. Lógica do Sentido. São Paulo: Perspectiva, 2007.

DEPRAZ, N., FRANCISCO J. VARELA \& VERMERSCH, P. On Becoming Aware: A Pragmatics of Experiencing. Philadelphia: John Benjamins North America, 2002.

ESPINOSA, Bento. Ética. Parte II (Da Natureza e da Origem da alma) e Parte III (Da origem e da Natureza das Afecções). Lisboa: Relógio D’Água, 1992.

EUGÉNIO, Fernanda; FIADEIRO, João. Secalharidade como ética e como modo de vida: o projeto AND_Lab e a investigação das práticas de encontro e de manuseamento coletivo do viver juntos. Urdimento - Revista de Estudos em Artes Cênicas / Universidade do Estado de Santa Catarina. Programa de Pós-Graduação em Tea- 
tro, Florianópolis, Vol. 1, no 19, p. 61-69, nov 2012.

EUGÉNIO, Fernanda; FIADEIRO, João. O Jogo das Perguntas. Lisboa: GHOST, 2013.

FISCHER-LICHTE, Estética de lo performativo. Madrid: Abada, 2011.

GUATTARI, F. A Revolução Molecular: Pulsações Políticas do Desejo. São Paulo, Editora Brasiliense, 1981.

GUMBRECHT, Hans Ulrich. Produção de presença: o que o sentido não consegue transmitir. Rio de Janeiro:

Contraponto/Ed. PUC-Rio, 2010.

JAEGER, Suzanne M. Embodiment and Presence. The Ontology of Presence Reconsidered. In: KRASNER, David. SALTZ, David.(orgs). Staging Philosophy. Intersections of Theater, Performance and Philosophy. Michigan: The University of Michigan Press, 2006.

MERLEAU-PONTY, Maurice. Fenomenologia da percepção. São Paulo: Martins Fontes. Tradução: C. Moura, (Texto original publicado em 1945) 1994.

NELSON, Lisa. BEFORE YOUR EYES: Seeds of a dance practice. New York: Contact Quarterly dance journal, v. 29, n. 1, winter/spring 04, 2003.

OLIVEIRA, Flávio; RODRIGUES, Sérgio. Affordances: a relação entre agente e ambiente. Ciências e Cognição. Revista interdisciplinar de estudos da cognição, v. 09, 2006, p. 120 - 130.

RANCIÈRE, Jacques. A partilha do sensível: Estética e política. Trad. Mônica Costa Netto. São Paulo: 34, 2005. RANCIÈRE, Jacques. O espectador emancipado. Urdimento - Revista de Estudos em Artes Cênicas / Universidade do Estado de Santa Catarina. Programa de Pós-Graduação em Teatro. Trad. Daniele Ávila. Florianópolis, v. 1, n. 5, p. $107-122$, out 2010.

SIMONDON, G. El Individuo y su Génesis Físico-Biológica (la individuación a la luz de las nociones de forma y de información). CaliI, Disuelta, 2007.

VARELA, FRANCISCO J.; THOMPSON, E. \& ROSCH, E. The embodied mind. Cognitive science and human experience. Boston: MIT Press, 1991. 